\title{
Human Capabilities and Human Authorities: A Comment on Martha Nussbaum's Women and Human Development
}

Robin West

Georgetown University Law Center, west@law.georgetown.edu

Georgetown Public Law and Legal Theory Research Paper No. 11-56

This paper can be downloaded free of charge from:

https://scholarship.law.georgetown.edu/facpub/286

http://ssrn.com/abstract $=1847987$

15 St. Thomas L. Rev. 757-790 (2003)

This open-access article is brought to you by the Georgetown Law Library. Posted with permission of the author. Follow this and additional works at: https://scholarship.law.georgetown.edu/facpub

Part of the Law and Gender Commons, and the Law and Society Commons 


\title{
GEORGETOWN LAW Faculty Publications
}

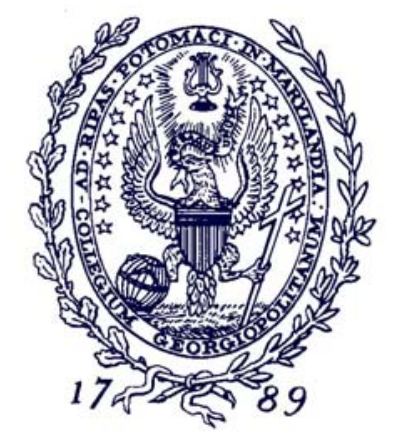

March 2010

\section{Human Capabilities and Human Authorities: A Comment on Martha Nussbaum's Women and Human Development}

15 St. Thomas L. Rev. 757-790 (2003)

\author{
Robin West \\ Professor of Law \\ Georgetown University Law Center \\ west@law.georgetown.edu
}

This paper can be downloaded without charge from:

Scholarly Commons: http://scholarship.law.georgetown.edu/facpub/286/

Posted with permission of the author 


\title{
HUMAN CAPABILITIES AND HUMAN AUTHORITIES: A COMMENT ON MARTHA NUSSBAUM'S WOMEN AND HUMAN DEVELOPMENT
}

\author{
ROBIN WEST*
}

SUMMER, 2000

What does it mean to be truly human? And, relatedly, what does it mean to be treated as truly human, and with dignity, by the state, or community, of which one is a part? To be fully human, Martha Nussbaum has argued for the better part of two decades, and argues in greater detail in Women and Human Development, is not only to be rational, and not only to be happy, but also to be capable - capable, for example, of loving others, of thinking rationally about one's own life, of engaging in dignified labor, of interacting with the natural and political environment, of participating in a society's cultural life. ${ }^{1}$ A truly human life is defined by, or perhaps constituted by, these capabilities; to lack any one of them is in some way to lack a fundamental pillar of one's humanity. ${ }^{2}$ Therefore, she continues, a citizen in a constitutional government is treated as fully human by the state when that person's fundamental capabilities - the capabilities which define her humanity - are, at least minimally, protected, promoted or nurtured by the state's governing authorities. Constitutional governments, then, whatever else they do, must protect, promote, or create whatever conditions are necessary for citizens to possess these fundamental capabilities. ${ }^{3}$ Sometimes, this obligation to promote or protect capabilities will impose constraints on what states might otherwise be permitted to do in order to promote other ends: general welfare cannot be promoted through state action if as a consequence the fundamental capabilities of citizens are adversely impacted. In this way, the state's obligation to protect human

* Professor of Law, Georgetown University Law Center.

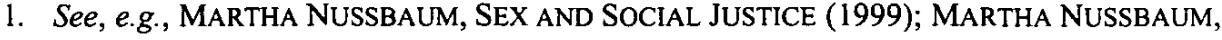
WOMEN AND HUMAN DEVELOPMENT: THE CAPABILITIES APPROACH (2000). For a full listing of Nussbaum's work on Capabilities, See MARTHA NUSSBAUM, WOMEN AND HUMAN DEVELOPMENT: THE CAPABILITIES APPROACH 34-35 n.2 (2000).

2. MARTHA NUSSBAUM, WOMEN AND HUMAN DEVElopMENT: THE CaPABILITIES APPROACH 5 (2000) [hereinafter WOMEN AND HUMAN DEVELOPMENT].

3. Id. at 4-11. 
capabilities limits the state's reach, in much the same way as does the state's obligation to protect rights. ${ }^{4}$ But at other times-and maybe more often - the state's absolute duty to protect the citizens' capabilities will impose positive, or affirmative obligations on states. A state, for example, is obligated to ensure through its laws and its expenditures, that every citizen has access to minimal food, shelter and health care, in order to protect the threshold capability of health. To take another example, it is obligated to ensure that children receive an adequate education, so that they will mature into adults capable of practical reason, and it is similarly required to ensure that children receive an adequately nurturant upbringing, to protect their present and future capacity for forming moral and emotive connections with others. ${ }^{5}$ Further, states must ensure through its laws, that adults have access to non-discriminatory and non-humiliating work, that all are protected through law against sexual and physical assault, that all have the capability of owning property and entering contracts, and so on. These obligations, clearly positive, are as fundamental on a capabilities approach to constitutional duties, as the more broadly or conventionally accepted obligation of the state, in a constitutional scheme, to protect individuals' negative rights of speech, thought, religious affiliation, and belief. Thus, unlike conventionally liberal "rights-based" approaches to states' powers and obligations, Nussbaum's "capabilities approach" envisions fundamental, non-negotiable, inalienable obligations of states that are positive as well as negative in character.

More specifically, Nussbaum argues, a human being possesses ten fundamental capabilities, all of which must be protected by the state if that person is to flourish as a functioning citizen. ${ }^{6}$ She must be capable of living a life of normal length. She must be capable of possessing good health, including reproductive health, food, and shelter. She must be capable of bodily integrity; free to move from place to place, with her bodily boundaries treated as sovereign. She must be capable of using her senses, imagination and thought in a way informed and cultivated by an adequate education. She must be capable of loving attachments, unblemished by fears and anxieties. She must be capable of practical reason-i.e., capable of forming a conception of the good life and capable of critical reflection on that life. She must be capable of forming meaningful affiliations with others and capable of being treated in those affiliations with dignity. She must be capable of living with concern for

\footnotetext{
4. Id. at 96.

5. Id. at $78-86$.

6. Id. at 78-80.
} 
and in relation to the world of nature. She must be capable of play. Lastly, she must be capable of controlling one's political and material environment. All of these capabilities are essential to human flourishing, and respect for human dignity requires all nations to protect these ten fundamental capabilities. As a matter of basic justice, all nations should be constitutionally committed to doing so.

In Women and Human Development, Professor Nussbaum develops this basic argument-an argument I will refer to as the "capabilities approach," and much of which she has spelt out elsewhere-in two directions. First, she develops-somewhat-the argument for the constitutional obligatoriness of the state's duty to protect fundamental capabilities. States everywhere, liberal and constitutional states in particular, should promote these capabilities, and should protect their minimal attainment. This is a basic, inalienable requirement of political justice. This is what a constitutional state must do if it is to treat its citizens with dignity and justice. This argument, which runs throughout the book, ${ }^{7}$ is best read and best criticized as a contribution to liberal political theory.

Second, Nussbaum demonstrates that a "capabilities approach" to constitutionalism, as outlined above, puts the problem and injustice of women's inequality in dramatic, sharp relief. If we assume, for a moment, that to be fully human is to possess these ten basic capabilities, and if we assume that a state treats its citizens justly and with dignity when the state protects those capabilities, then it is vividly clear that states everywhere are unjust toward women, and that women are not treated with dignity by the states of which they are citizens, anywhere. As Nussbaum states in her opening paragraph:

Women in much of the world lack support for fundamental functions of a human life. They are less well nourished than men, less healthy, more vulnerable to physical violence and sexual abuse... less likely than men to be literate ... still less likely to have preprofessional or technical education ... are not full equals under the law; do not have the same property rights as men, the same rights to make a contract, the same rights of association, mobility, and religious liberty, [are more] burdened with the 'double day' of taxing employment and full responsibility for housework and child care, ... lack opportunities for play and for the cultivation of their imaginative and cognitive faculties .... have fewer opportunities than men to live free from fear and to enjoy rewarding types of love .... In all these ways, unequal social and political circumstances give women unequal human capabilities. ${ }^{8}$

7. Id. at 4-11, 101-106.

8. Id. at 1 . 
While many states (including the United States) fail to protect all of their citizens' capabilities in fundamental ways, both in theory and even more so in practice, women's capabilities - everywhere-are not as protected, nurtured, or promoted as those of men's. This inequality emerges, in Nussbaum's account, as a massive, indeed global, problem of injustice: governments everywhere fail, and often quite dramatically, in their most basic constitutional obligation toward their female citizens.

Consequently, Nussbaum concludes, if we wish to assess the progress of various states toward the goal of treating their female citizens and their male citizens in a roughly equal way, we should use the fundamental capabilities as a sort of benchmark. A state that protects the fundamental capabilities of men and women equally (whatever that requires in terms of allocations of resources) and above a minimal threshold is treating its citizens justly, at least as regards gender inequalities.

So, the basic thesis of Women and Human Development is that governments everywhere have a constitutional obligation to promote their citizens' fundamental human capabilities, and that governments everywhere fail to promote women's capabilities to the same extent as men's, sometimes dramatically and brutally so. In fleshing out these two arguments, Nussbaum does much else besides. She persuasively argues, that the "capabilities approach" she defends not only provides a better foundation than competing (and sometimes quite similar) welfarist conceptions for assessing the comparative well-being of nations (an argument pioneered by Armatya Sen) but also provides a better set of principles for constitutional governance. ${ }^{9}$ She effectively critiques cultural relativism and moral relativism, and defends the universalist thrust of her own approach (as well as of liberalism generally), against relativist objections. ${ }^{10}$ These capabilities, after all, are human capabilities, not American capabilities, or Indian capabilities, or liberal capabilities, and it is incumbent upon governments everywhere to protect them. Using India and its constitutional democracy as an example, Nussbaum devotes a chapter to defending this universalist claim against the objection that no such sweeping moral truths exist, or should be applied as yardsticks, even academically, against states, such as India, with different histories, cultures, and moral systems of belief. Third, she nicely shows in two extended discussions how her own approach to what states must and should do parallels that of John Rawls, and how it importantly differs: she embraces and adopts his idea of an overlapping consensus as providing justification

9. Id. at 4-11; at 111-161.

10. Id. at 34-110. 
for public rules, but finds in the overlapping consensus a set of human capabilities which states must protect, rather than a set of individual rights or primary goods. ${ }^{11}$ Fourth, she goes to some lengths to show that, appearances to the contrary notwithstanding, her approach is fundamentally liberal: prominent on the list of capabilities a state must protect is our capacity for rational action, and this prominence minimizes, she believes, the degree of (allegedly) illiberal paternalism a capabilities approach requires. ${ }^{12}$ Fifth, here as everywhere in her writing, narrative plays a prominent role; she effectively employs the stories of a handful of Indian women to illustrate the potentials and perils of her "capabilities" approach to government. ${ }^{13}$ Relatedly, she places a heavy and signature emphasis on the importance of moral education and moral sentiment to civic life and responsibility. Finally, she unabashedly and unqualifiedly insists that global development efforts must be feminist if they are to be either just or effective. ${ }^{14}$ It is a declaration both heartfelt and heartening, and a stance that $I$ think is courageous.

I generally agree with most of these subsidiary arguments and will not discuss them further. For the most part they are not what is new or most interesting in this book. I also agree, in broad outline, with Nussbaum's general thesis (which is both new and interesting): to wit, that governments ought to protect the fundamental capabilities of their citizens, that this is or ought to be a constitutional obligation, and that as things stand most and maybe all states fail to do so with respect to women. What I want to do in this review is comment on one aspect of the thesis, at least as presented in this book, that in my view warrants further development. Nussbaum simply does not pay close enough attention to the role of authority-both in the real world and in the utopian world she imagines - in constructing a state role in the development and protection of human capabilities. My general claim, which I will try to make out piece by piece in the various sections below, is that Nussbaum's evident, admirable, and generous liberalism-her high regard for individual choice, the absolute value she places on the dignity of every human being; her commitment to the centrality of practical reason to a well-led life; her Rawlsian search for an overlapping consensus to justify political norms; and in general her attentiveness to the lessons of individualism and individual worth that have always constituted the heart of liberalism-although in many ways a strength of her overall approach, comes with a price: the quintessentially

11. Id. at $64-70,88-91$.

12. Id. at 59-60, 51-55.

13. Id. at 15-24.

14. Id. at 4. 
liberal spotlight on individual autonomy can cause a sort of blindnesssometimes, perhaps, willful blindness, sometimes just inattentiveness- to the presence of, damage done by, and sometimes the need for, social, political and moral authority. The manifest liberalism of the capabilities approach, as championed by Nussbaum in this book, pays that price as well.

Entirely aside from theoretical problems in liberal theory, I think there are two "character-based" reasons that inattentiveness to the problems and promise of authority might be a distinctively liberal failing, both of which are borne out by Martha Nussbaum's persona and her book. First, liberalism is a faith steeped in optimism, as is Martha Nussbaum and as is this book: liberals tend to see and magnify liberty, individualism, willfulness, openness and liberality where there may in fact be only the faintest hint of any of that. Consequently, they often see liberty or choice where others see, beneath the surface or perhaps not so far beneath, coercion and masked power. Second, liberalism is utopian and universalist, as is this book, through and through. Liberals justify state power by reference to moral principles grounded in universal traits of human nature and authority, for better or worse, is particular, concrete, and local. For both reasons, and as liberalism's critics have long maintained, liberals somewhat notoriously see freedom where there is in fact restraint, and liberty where there is in fact authority, and general principle where there is in fact real politik, and run the considerable risk of appearing complicit in both the exercise and masking of illegitimate power, when they render false judgments accordingly.

In Women and Human Development, this selective blindness sometimes (although not very often) comes in the form of apparent naivete regarding the fist in the velvet glove of social and cultural authority, and the damage thereby occasioned. It in turn, I think, somewhat weakens, Nussbaum's extended treatments of family law and religion law, each of which is given a full chapter, and each of which is intended to exemplify the strengths of a capabilities approach. ${ }^{15}$ In both of those chapters, by seeking to accommodate the liberal freedoms of individuals to believe and affiliate without undue interference by the state, Nussbaum opens herself to the charge that she sees religious liberty where there is in fact religious authority, and chosen familial affiliation where there is in fact little but cruel human bondage. Even more often, though, and I think a more serious shortcoming of the book, her characteristically liberal blindness to (or, perhaps, just lack of interest in) actual authority comes in the form of a

15. Id. at 167-240, 241-97. 
hesitancy regarding possible sources of authority for her own conception of the role of human capabilities in political thought and action. That hesitancy then paradoxically weakens the argument's power. By not attending to authority-constitutional, cultural, and moral-and the ways in which such authorities could strengthen the case for a state role in protecting human capabilities, she is paying some pretty heavy opportunity costs.

In these comments, I want to fill in that gap. I will highlight and then amplify what I think is missing or underplayed in Nussbaum's treatment of capabilities and women, and that is the role that authority plays-and the role it should and should not play-in guiding states toward a recognition of their obligation to nurture, promote, or protect women's-and men's and children's-human capabilities.

\section{LEGAL AUTHORITY, CONSTITUTIONS, AND REAL POLITIK}

Women and Human Development is a frankly utopian text. Although much of the argument is carried by the narratives of particular women's stories, and although a number of legal discussions of particular issues are sprinkled throughout, nevertheless, the general prescription and the general thesis are strictly in the realm of the ideal. Ideally, constitutional governments ought to promote the capabilities of their citizens; ideally, capabilities ought to inform the principles by which constitutions direct and constrain government. There is not a lot of attention paid to how developing governments are to go about doing this when they don't have the resources to do so even if they wanted to, and even less devoted to how or whether recalcitrant governments might be persuaded or forced to protect their citizens' capabilities. Even more striking, however, than the inattentiveness to politics, is the inattentiveness (or, more accurately, the only spotty attentiveness) to law. Although there is plenty of legal discussion, there is virtually no sustained legal argument, constitutional or international, to the effect that all governments, or all constitutional states, or India, or the United States, as a matter of either domestic or international constitutional law, must-legally must-somehow go about doing this, beyond fairly general assertions that some constitutions, world wide, already codify a mandate to protect some of these fundamental capabilities. Nor is there any argument, constitutional, international, or otherwise, to the effect that well off countries must-legally must, and not just morally must-assist, through wealth transfers, those countries who presently lack the capacity to promote or protect their citizens' capabilities. There is, in other words, no argument for the capabilities approach, from authority. 
Let me make a little clearer what in my view is missing, and then expand a bit on its implications. First, Nussbaum makes clear early on, in a section specifically addressing problems of "implementation," that she does not intend her capabilities prescription as a guideline for an international or transnational meta-constitutional system: the idea put forward in this book is emphatically not that an international board or international court should police nation-states for compliance with an international norm-either actual or ideal-that codifies the mandate that states must promote their citizens' capabilities. ${ }^{16}$ Even less is she asserting that some international authority should have the taxing authority to redistribute wealth so as to make it possible for all nation states to do so-although she does acknowledge, almost as an aside, that some measure of redistribution across nations will in fact be required. She accordingly makes no argument to the effect that present international human rights law, for example, properly read, already imposes such obligations on states. ${ }^{17}$ Rather, she emphasizes several times that implementation, when and if it occurs, must be through the vehicle of each country's domestic constitution, and not through international law.

Nor, however, does she make a constitutional argument, either generally, or with respect to any particular country's constitution, regarding the constitutional obligatoriness of the capabilities approach. Thus, nowhere does she claim that either the Indian Constitution, or any other democratic or liberal constitution, has already codified the mandate to protect citizens' fundamental capabilities. ${ }^{18}$ Nowhere does she make the sort of Dworkinian claim that even the United States Constitution, best read in accordance with some specified set of moral and political principles, impliedly embraces a capabilities approach. There is, to repeat and sum up,

16. Id. at 103-04. At most, she urges nations that have already adopted a capabilities approach, and that have the power to do so, to impose economic sanctions against states that egregiously fail to meet the minimum threshold requirements. Unfortunately, she does not take up the often-times disastrous humanitarian effects of sanctions, as we have witnessed them in the last twenty years of their use. Sanctions almost by definition inflict damage on the very human capabilities of citizens the denial of which motivated their imposition, rather than direct political or military costs on the state's leaders. The capabilities approach would seem to suggest an argument against, not for, economic sanctions.

17. She does suggest that current human rights law in some ways is supportive of a capabilities approach, but the basis of the support, or the implications of it, are not spelt out. Id. at 104-05.

18. She does make the weaker claim that Indian constitutional law generally supports the approach she takes to issues of religious freedom, and that United States constitutional law as well contributes useful suggestions. See id. at 198. But even assuming this is correct (and there's no demonstration beyond the assertion that it is) that is a long way from a constitutional argument for the capabilities approach writ large. 
no sustained argument for the capabilities approach from authorityinternational, constitutional or otherwise. There is nothing that either an international lawyer or a constitutional lawyer, whether American or Indian, (the two major legal systems she explores) will recognize as a legal argument for the capabilities approach to just governance.

This is not a casual omission. Rather, when describing the status of her own contribution, Nussbaum goes out of her way to make it clear that she is not making such an argument. Thus, after briefly summarizing the fundamental capabilities approach, she pointedly characterizes it as "a good idea" and a "good idea" only. ${ }^{19}$ Partly to ward off charges of imperialism, but partly to make clear the limitations of her own case, Nussbaum explicitly denies that she is invoking any sort of legal authority, constitutional or international, for her position. Rather, she says, the capabilities approach is simply a "good idea" that the government of the United States or India ought to employ, and implement through constitutional mechanisms. If the governing authorities in constitutional governments can be persuaded to do so, they ought to reconstitute themselves, in effect, and commit their constitutions and states to promoting and protecting human capabilities. The book is an argument for why this would be, all things considered, a good thing to do. It's nothing less than that, and most assuredly nothing more.

I think this disavowal of, and then inattention to, international, constitutional, and legal authority is unfortunate, and for four reasons. The first is rhetorical. The claim that constitutions ought to require states to protect human capabilities, suggests either a call for constitutional redrafting and conventions, or an argument about what constitutions, properly read, already say. The reader is disoriented when no such argument, and no such call, is made. The second is logical: Nussbaum's argument, to be complete, requires some attention paid to constitutional theory. The claim that constitutions ought to require the protection of human capabilities suggest some view of what it means to have a constitution in the first place. That view might be right or wrong but it needs to be spelt out. The third is pragmatic. In many nations, perhaps, and very likely in the United States, constitutions, as presently construed, might be more of an obstacle to rather than a vehicle for the capabilities approach, and if this is right, then especially in a time when United States constitutionalism is being exported globally, reliance on constitutionalism ought to come with at least a warning attached for anyone interested in a capabilities approach to just governance. The last is idealist, and to me

19. Id. at 103 . 
most important. There are, I think, strong arguments that can be made, both for the constitutional necessity of the capabilities approach under the United States constitution, as well as more generally: constitutionalism, properly understood, does, I think, imply the constitutional obligatoriness of state protection of citizens' capabilities. We've lost an opportunity by not having those arguments articulated in this otherwise powerful book. Because these concerns are admittedly disjointed, I'll spell them out separately below.

\section{A. THE IDEAL, THE REAL, AND LEGAL RHETORIC}

First of all, the implicit rejection of even the relevance of actual constitutional law to her overall argument is going to leave readers who are also lawyers - and this seems to be a large chunk of the intended audience-disoriented. Lawyers are accustomed to seeing these sorts of arguments about what a constitution means or should mean in the context of disputes with implications for real cases, and anchored in some sort of reading of some part of a constitutional text. The "constitutional" argument here, by contrast, is both profoundly ahistorical and noncontextual. The "constitution" that the argument envisions, which ideally requires whatever state it constitutes to protect the capabilities of citizens, is a fantasized constitution: it is an open-ended, benign, and liberal text, free-floating, in search of a capabilities approach to anchor it. It doesn't have any actual terms, phrases, or articles. It doesn't have a history. It is a constitutional idea, not a constitutional fact. In the real world, though, legal argument, and particularly legal argument about what constitutions require, is (perhaps notoriously) a distinctive blend of ideal and fact, of norm and history. Nussbaum's fundamental capabilities approach is ultimately a constitutional argument with a constitutional conclusion, but it bears no resemblance to conventional understandings of what such arguments contain. The radical departure from the form of constitutional argument-in what otherwise appears to be a constitutional argumentwill disorient lawyers.

But I think that even beyond the legal audience, the lack of anything resembling a legal argument for what turns out to be, basically, a legalistic and constitutional thesis-that constitutional governments are constitutionally obligated to protect their citizens' fundamental capabilities-will leave general readers puzzled as well. For non-lawyers as well as lawyers, it seems that an argument about what constitutional democracies are constitutionally required to do for their citizens should have some treatment of what constitutions actually do or say, even in 
liberal democracies that arguably come close to the prescribed ideal, and certainly in illiberal ones that are nowhere near. Of course, Nussbaum is not the only theorist to take up the question of the requirements of justice, and then to eschew discussion of law. Rawls' $A$ Theory of Justice $e^{20}$ is an obvious example of a classic treatment of the requirements of justice in the liberal state that is at least as equally inattentive to problems of authority. But there are two major differences between Rawls and Nussbaum's approach, in addition to the differences she catalogues, that bear on this question. First, Rawls, unlike Nussbaum, puts no faith in constitutions as the vehicle for bringing recalcitrant states in line, and therefore Rawls' thesis doesn't itself raise expectations that an actual constitutionsomewhere, somehow-might actually impose such requirements. Second, and perhaps more tellingly, in some of the liberal societies touched by Rawls' ideas, authoritative pronouncements by Courts and commentators regarding the requirements of constitutionalism were in fact not so far removed from the ideal he sketched out in his classic text. Thus, it might truly be said that not only settled moral intuitions, but even some settled legal and constitutional practices, lent support (albeit indirect) to Rawls' thesis. It was not at all difficult, in other words, particularly around the time Rawls' work was published, to imagine the United States Constitution being read by a liberal court in such a way as to bridge the ideal-to-real gap between Rawlsian theory and constitutional reality. Shortly following its publication, in fact, a cottage industry of lawyers began to do precisely that. $^{21}$

Nussbaum, by contrast, has different ambitions and faces different challenges. Nussbaum, unlike Rawls, thinks justice, as defined in part by the capabilities approach, should constrain governments everywhere, not just in liberal societies that already come somewhere close to the ideal, and in even clearer contrast to Rawls, she explicitly envisions it happening through the authority of their own domestic constitutions. So the ambition is different: Nussbaum's approach stands ready to be implemented, through constitutional processes. This alone raises an unmet expectation that constitutional authority will be invoked as an argument for the capabilities approach. But perhaps more important, and again in contrast to Rawls, the sheer magnitude of the gap between the conditions of the women's lives

20. JOHN RAWLS, A THEORY OF JUSTICE (1971).

21. Perhaps the best attempt to translate Rawlsian justice into constitutional law was Frank Michelman, In Pursuit of Constitutional Welfare Rights: One View of Rawls' Theory of Justice, 121 U. PA. L. REV. 962 (1973). Dworkin also urged that the United States Constitution both could and should be read so as to bring it in line with Rawlsian liberalism. See RONALD DWORKIN, TAKING RIGHTS SERIOUSLY vii, vii-xv (1977). 
(and most men's as well) she discusses and the apparent disregard of states toward those women's capabilities, on the one hand, and the minimal obligations she thinks all constitutional governments have toward their citizens, is enough to give the reader vertigo; it is simply much larger than the gap between justice, as understood by various liberal constitutional authorities (including some Supreme Court Justices) in the mid 1970s, and as understood by John Rawls. So the challenge is different as well: "implementation" of Rawls' requirements of justice could occur (or could have occurred; the moment has likely passed) through normal processes of constitutional interpretive evolution, at least in some democracies, whereas "implementation" of Nussbaum's requirements of justice will minimally require both substantial redistribution of wealth between nations and revolutionary overhaul of governing domestic structures in, possibly, all states, as well as a re-thinking of governing constitutional principles. None of that seems imminent.

For both reasons-Nussbaum envisions nations codifying the capabilities approach in their constitutions, and as she acknowledges, the gap between her ideal of justice and the practices of government in the states she discusses is unfathomably huge - the reader of Nussbaum's book quite naturally begins to crave just a touch of real politik. What, if anything, is going to impel governments, either first world, third world, developing, developed, liberal, illiberal, democratic, or dictatorial, to pay the slightest attention to any of this? What is going to impel developed countries to distribute wealth in a way that will facilitate the constitutional process in developing countries? This book doesn't even hint at answers, other than to note that "implementation" will be difficult. But this is not a satisfactory response. For Nussbaum, more than for Rawls, the unanswered question of political authority-how any of this could ever happen, in a world dominated by ethnic nationalism and economic globalism - simply dwarfs the question of justification she does take upwhy this should happen - and is indeed, in complex ways, a part of it.

\section{B. Constitutional Meaning}

Second, the lack of attention in Women and Human Development to constitutionalism, constitutional doctrine, and even constitutional theory, is unfortunate for a formal, or logical reason: Nussbaum's argument, to be complete, needs at least a theory of constitutionalism, if not a full fledged constitutional argument. If the fundamental capabilities are to undergird principles that are in turn to be constitutional, as Nussbaum advocates, then we need an argument about what constitutions are, can be, have been, and 
should be in the future. But there is no theory, or even description, of constitutionalism, accompanying the political theory that is intended to supply these constitutions' content, at least in this work.

Let me explain why this omission matters. Nussbaum seems to envision the idea of constitutionalism in what I would regard as a typically liberal-legal way, although nowhere does she spell this out: a constitution, liberally understood, and I think as understood by Nussbaum, should embody moral principles of governance, that are in turn drawn from some conception of our universally shared human nature. The constitution, so understood, then constrains and directs states accordingly. The principles Nussbaum derives, and the conception of human nature she spells out, are quite different from those of other major liberal theorists. Nevertheless, in its reliance on moral principles, universalist in scope, and drawn from an understanding of human nature, the overall orientation toward the idea of constitutionalism is markedly liberal.

This is, most assuredly, one way to think about constitutions and it is a powerful one. The problem is that there are other, perhaps equally powerful ways to think about what constitutions are and what they do, and what they should be, and what they should do. It may be, for example, that a nation's constitution should embody moral principles of governance drawn not from some conception of universal human attributes, or capabilities, or rights, but rather, from the nation's particular and particularizing history: this understanding, or something like it, surely underlies originalist or intentionalist understandings of constitutional law in our own country. Or, perhaps, (and perhaps more plausibly), the moral principles of governance embodied in a nation's constitution should be drawn neither from universal principles nor the nation's particular history, but rather, from its self-regarding myths, or narratives, or stories, whether fictional or factual, about its history, and that have in turn, and over time, constituted the "people's" moral self-identity. The United States constitutional law of race relations, for example, on this "mythic" understanding of constitutionalism, might sensibly be "read" as including not only the text of the reconstruction amendments, Brown v. Board of Education, ${ }^{22}$ and Crosun v. City of Richmond, ${ }^{23}$ but also the story of the slave rebellion at Harper's Ferry, Harriet Tubman's heroic underground railroad, Harriet Beecher Stowe's Uncle Tom's Cabin, Mark Twain's Huckleberry Finn, Richard Wright's Native Son and so on. On either the historical or mythic understanding of constitutionalism, and what it means

22. Brown v. Board of Ed., 347 U.S. 483 (1954).

23. Crosun v. City of Richmond, 488 U.S. 469 (1989). 
for a nation to have one, the moral guidance provided by a Constitution defines and delineates "the People," by marking off the country's history, and hence its moral commitments, from other world inhabitants. There may be some other source of law, and hence legal authority, that imposes obligations on nation states derived from universal truths of our nature, but constitutional law can not be it, if constitutional law, and constitutionalism generally, and by definition, is about a country's distinctive, rather than its universal, moral commitments, and if those commitments are and should be derived from the nation's distinctive history, rather than from its inhabitants universal nature.

We might, in fact, think of various theories of constitutionalism along a continuum, defined by this "particularist-to-universalist" axis. At one end are views of constitutionalism that see the role of the constitution as delineating a national identity, by in effect highlighting and sharpening distinctive events, features, and moments of the nation's shared history. At the other end are views of constitutionalism that see the role of the constitution as imposing constraints, in the name of universalist conceptions of humanity, on just that sort of national distinctiveness: the purpose of the constitution, in other words, as understood at this end of the spectrum, is to require of the state obligations derived not from the country's history, but from the human status of the state's citizens. If so, then constitutions are universalizing, rather than particularizing, documents. Liberal theories of constitutionalism tend toward the universal pole, while communitarian and conservative theories tend toward the particular. In the United States, disputes over constitutional doctrine, as well as constitutional method and appropriate sorts of interpretive methods are, among much else, in part over just this universalist versus particularist sort of split. If the constitution is necessarily about what makes us distinctive, because that's just what a constitution is, then the intentions of the framers, our country's various "constitutional moments," and (arguably) Uncle Tom's Cabin, (or some subset of those historically specific events) must be consulted as "authoritative" sources of constitutional law -they are part of our constitutional story. If, however, the Constitution is fundamentally about not what makes us truly American, but what makes us truly human, then the requirements imposed upon states to treat human beings with dignity, and not our distinctive history, are authoritative. If so, then a consensus of the sort Nussbaum hopes to build, across nations, cultures, and peoples, rather than historical-national events of character building, is indeed the evidence we need to interpret or create a 
morally just constitution. ${ }^{24}$ Again, either pole of this axis, as well as any number of mid-way points along it, are plausible enough accounts of the way the idea of constitutionalism has been bandied about in theory and used in practice, at least in the United States. And precisely because of that apparent plausibility, some sort of argument, or at least some sort of account, is needed, in support of a universalist, rather than particularist, approach to constitutionalism. Nussbaum's "capabilities" approach to constitutional governance, because it explicitly aims to marry liberal political theory with the promise of constitutionalism, clearly requires such an argument.

\section{Constitutional Problems}

Third, Nussbaum's relative inattention to actual constitutional law (and to constitutional theory) means that she has failed to attend to those moments in our own, domestic, United States constitutional history, including arguably the "moment" we are currently in, during which both our particular constitution and the idea of constitutionalism more broadly have been authoritatively construed as hostile to anything even approaching a capabilities approach to moral governance. Obviously, such moments might be perversions of true constitutionalism, but on the other hand they might be paradigm-creating moments, depending on one's point of view. Either way an argument is required, and here at least, none provided.

To revert to a sixties slogan, Nussbaum optimistically assumes that constitutions will in some fashion be "a part of the solution" rather than a "part of the problem;" that constitutions can be drafted, and if already drafted can be read, as imposing obligations on states to protect human capabilities. But this optimism ignores sizeable chunks of actual constitutional history. If, for example, we read the old turn-of-the-century notion in United States constitutional history of the state's "police powers" over matters pertaining to the citizens' health, morals and safety, as roughly analogous to Nussbuam's conception of the state's "police power" to protect the citizens' capabilities, then its clear enough that at least during the Lochner era, in United States Constitutional law, the Court read the Constitution as limiting the state's power to do precisely what Nussbaum argues the state should be constitutionally obligated to do. At the time, the Court reasoned that such expansive police powers posed too great a threat to individual economic liberty, particularly the economic liberty of

24. Nussbaum suggests that she is in the middle of a "consensus-building" project for the capabilities approach, consulting with women, activists, and state officials from a number of countries on the capabilities list. See WOMEN AND HUMAN DEVELOPMENT, supra note 2, at 102. 
employers and property owners to put their capital to whatever end they saw fit. Presently, the current court is reading the Constitution as limiting the federal government's power to protect women and children's safety, and hence their capability to live a fully and healthy life free of fear and abuse, rather than obligating it to do so. It is doing so, these days, not so much out of libertarian worries regarding the freedom of capitalists, but rather, from federalist concerns regarding the power of states vis-a-vis nations in a federalist system. But now, as then, the Constitution is being authoritatively read as limiting the government's power to protect human capabilities, rather than obligating it to do so.

Obviously, these moments-the Lochner era, and the current Bronzkala era-might be anomalies. In fact, the United States Constitution itself, along with its manifest hostility toward the redistribution required to meet the minimal requirements of a "capabilities approach," might be an anomaly - a product of a particular historical moment, dominated by fears of redistribution and an excessive commitment to private power. It might be that, overall, the idea of constitutionalism and the world's various constitutions will prove to be a powerful force not only for liberalism, but for a capabilities-based liberalism. But it is not at all clear that the current zeitgeist is pushing us toward such a happy evolution. In fact, it seems more likely, right now, that Lochner and Bronzkala are paradigmatic moments rather than anomalies: the impulse toward minimal state authority for even human well-being, much less for the equal human capabilities of all citizens, that they articulate, might be emerging as the constitutional impulse. If so, then we may be in the process of forging a deep, and not just an incidental or bounded alliance between the idea of a constitutional government, and the idea of a minimal government. And if that is in fact occurring, then it is also likely that the combined globalization of markets and the internationalisation of the idea of law will push not only particular constitutions but even the idea of constitutionalism toward a decidedly minimal conception of state authority - and therefore push states toward a minimal, rather than capacious, responsibility for human capabilities. Finally, should that come to pass, advocates of a capabilities approach to just government will have to urge such an approach as a constraint on constitutionalism, rather than a force in tandem with constitutionalism, and will have to find authority for it elsewhere than in nations' domestic constitutional law.

None of this is writ in stone, and all of it could have been and might in the future be otherwise; there is nothing about the abstract idea of a constitution that necessarily implies minimal state authority for either capabilities or rights. Nevertheless, there is surely, at this point in the new 
millennium, good reason to be skeptical of the claim that constitutionalism will be a vehicle for a capabilities-based liberalism, or, for that matter, for any liberal, universalist conception of government that seeks to impose constraints on market based outcomes. Constitutions might emerge in the next century as tools for reform, or they might emerge as tremendously regressive obstacles to any sort of liberalism, and on both an international as well as domestic scale. And of course, maybe most likely, they might emerge as ambiguous tools, sometimes progressive and sometimes regressive, sometimes entrenching nationalism and sometimes the opposite, sometimes mandating respect for human capabilities, sometimes not. Right now, at least domestically, the United States Constitution is more of a problem for a capabilities based approach to just governance than a vehicle for it. As the United States Constitution becomes a model for developing nations internationally, there is reason to worry that its regressivism will be one of our more shameful exports.

\section{Constitutional Promise}

On the other hand, there are countervailing tendencies in even American constitutional law, and there are certainly countervailing tendencies in constitutional theory, and its worth spelling those tendencies out. There may well be a solid, credible, even compelling argument-or arguments- - to the effect that the United States Constitution requires states to attend to the capabilities of its citizens, and there may also be good arguments to the effect that the idea of constitutionalism should tend states toward a capabilities approach. If there are such arguments, then the greatest cost of Nussbaum's relative inattentiveness to actual constitutional authority is her failure to put those arguments forward.

I think there are such arguments, and that they are worth spelling out, even if only briefly. First, (and in addition to the fundamental rights authority under the due process clause, which she does cite as providing possible tangential authority for a capabilities approach $)^{25}$ the United States Constitution's Fourteenth and Fifth Amendments include a requirement that states provide "equal protection of the law." Courts and commentators have parsed the term "equal" in that phrase endlessly, but relatively little attention has been paid to the clause's actual requirement, which is that states must provide protection; "equal" is the modifier, to provide protection is what states must do. If we pay attention to the plain language of the text, it should be clear that the Constitution requires states (and

25. WOMEN AND HUMAN DEVELOPMENT, supra note 2, at 202. 
congress, if states fail to act) to protect their citizens, and to protect them through law, and to provide the protection equally. The phrase, by its language, clearly imposes positive obligations on states-the positive obligation to protect, and to do so equally.

What the phrase does not do is specify what the citizen must be protected, through law, against. Given our own history-and particularly the history of unchecked white-on-black violence against African Americans, first during slavery, and then after it-it seems sensible enough to read the phrase as requiring the states to provide all citizens with protection against private violence, and to provide that protection equally. The state must provide that protection, and citizens do indeed have a right to it-declarations of the current Court to the contrary notwithstanding. ${ }^{26}$ There does seem to be explicit constitutional authority, in other words, for the Nussbaumian claim that the state has a constitutional obligation to protect citizens' capability to live a life of ordinary duration, free of abuse and violence, and the fear and degradation of health that accompanies it. There does seem to be, then, explicit constitutional authority for the related claim that a state must provide this protection to male and female citizens, as well as white and non-white citizens, equally.

The harder question in United States constitutional law is whether the state's Fourteenth Amendment-based duty to protect its citizens extends beyond the duty to provide protection against violence. Is there a constitutional obligation to provide protection against other possible violations of our fundamental capabilities? The question is obviously wide open, but a few possible arguments-arguments from authority, so to speak - are worth noting. First, as Nussbaum argues, there is indeed good reason-Nussbaum has articulated what that reason would be - to read the phrase broadly. To be truly human is to be capable, and to be treated with dignity is to be treated in such a way that one's capabilities are nurtured and then protected. But this "good reason" is not, her own hesitancy notwithstanding, just a "good idea." More strongly, if Nussbaum is right, then justice requires states to protect the citizens' fundamental capabilities, and the Constitution quite generally requires states to behave justly toward citizens. The conclusion, then, should be clear enough; the Constitution generally and the fourteenth amendment in particular, requires the states to protect what needs to be protected in order to fulfill its mandate of justice.

26. The Court has denied that the Constitution generally and the 14th Amendment in particular imposes any positive obligations on states, and specifically that it imposes any positive obligation to provide a police force. See Deshaney v. Winnebago County Dep't of Soc. Services, 489 U.S. 189 (1989). 
Second, it might also be argued that constitutional authority emanates not only from explicit textual provisions of the Constitutional text, but also from what Bruce Ackerman provocatively calls a culture's "constitutional moments": moments in which constitutional understandings are fundamentally altered, whether or not through the formal amendment process. We might be in such a moment, and it might be a "moment" that is tending toward recognition of a "capabilities" approach to just governance. There are signs of an emerging "capabilities moment" scattered about the current legal and political landscape. First of all, much of the 1960 s to 1990 s constitutional doctrine surrounding sex equality can easily-perhaps most easily - be read as underscoring the obligation of states to protect women's equal capabilities (rather than equal rights): capabilities for dignified work, ${ }^{27}$ reproductive health, ${ }^{28}$ access to property and contract ${ }^{29}$ and non-humiliating and non-discriminatory treatment in the private sector. ${ }^{30}$ Outside the courts, however, we also see movement toward a re-constituting of our understanding of federal and state responsibility for citizens' capabilities. The flawed and inadequate Family and Medical Leave Act, for example, and even the conservative "welfare reform movement," although cruelly punitive and heavy-handed, if read in a "best lights" spirit, tends toward a capabilities approach: the goal of both the Family and Medical Leave Act ("FMLA") "31 and the Personal Responsibility and Work Opportunity Reconciliation Act ("PRWORA"), according to at least some of their proponents, was to promote and nurture women's capabilities - the capability to work, to achieve independence, and to affiliate with and care for their dependents. The now-stalled movement toward legal recognition of gay and lesbian intimate partnerships, and ultimately perhaps same-sex marriage, likewise, clearly conduces toward legal protection of a fundamental capability of intimate affiliation. The newfound interest across the political spectrum, but

27. See Meritor Savings Bank v. Vinson, 477 U.S. 57 (1986); see also Harris v. Forklift Systems, Inc. 507 U.S. 959 (1993).

28. Roe v. Wade, 410 U.S. 133 (1973); Planned Parenthood of Southeastern Pa. v. Casey, 505 U.S. 833 (1992) (both make capabilities the centerpiece of the constitutional analysis, albeit without saying so).

29. See Reed v. Reed, 404 U.S. 71 (1971); see also Frontiero v. Richardson, 411 U.S. 677 (1973).

30. See Virginia Military Institute v. United States, 508 U.S. 946 (1993).

31. Family and Medical Leave Act of 1993, Pub. L. No. 103-3, 107 Stat. 6 (codified as amended in scattered sections of 2 U.S.C., 5 U.S.C., and 29 U.S.C.).

32. Personal Responsibility and Work Opportunity Reconciliation Act of 1996, Pub. L. No. 104-193, 110 Stat. 2105 (codified as amended in scattered sections of 7 U.S.C., 8 U.S.C., 21 U.S.C., 25 U.S.C., and 42 U.S.C.). 
importantly including the republican party, in defining a robust federal role in the education of children, in maintaining and strengthening Head Start programs, in expanding and even guaranteeing some measure of health care, in providing some sort of gun control legislation and expanded remedies for victims of domestic violence, and very generally for recovering the "lost opportunities of those left behind," all are suggestive of a "re-constituting" of our sense of national self identity, and in a way that protects fundamental capabilities.

Of course, even if this optimistic reading of the current political climate is fair, it goes without saying that flawed and punitive "work and parenting" legislation, a fledgling and embattled gay rights movement, sputtering political movements for rights to health care or gun control, and chronically under funded head start programs, are a long way from a recognized constitutional right to meaningful work, to adequate education, to intimate associations, to safety, to nutrition, and health. Nevertheless, the breadth of support for all of these positions is important and suggestive, and what it suggests, I think, quite broadly, is a growing popular consensus over some sort of capabilities-based approach to governmental responsibility. Should that consensus grow, and should it develop into a sense that the government is required, and not just permitted, to enact legislation of just this capabilities-protecting sort, then it would not be out of bounds to view that development as a "constitutional moment." And should that come to pass, in much the way Ackerman has so thoroughly described, such moments do indeed come to possess considerable, even defining, constitutional authority. ${ }^{33}$

Fourth, some authority for the capabilities approach might be found in the Hobbesian contractual metaphor that in some rough way underlies the phrase "We the People," with which the United States Constitution opens. Nussbaum alludes at various points in her text to the potential consensual underpinnings of the capabilities approach. ${ }^{34}$ It is because some consensus over these capabilities is at least imaginable, and to some degree already evidenced, across cultures and generations, that one can say that protection of citizens' capabilities ought to be a constitutive function of government. Although she doesn't make the argument, it seems fair to say that the same potential consensus suggests constitutional authority for that function as well. The idea of constitutionalism alone surely does not mandate any particular democratic form of government. But it does suggest a deliberative moment in which the state commits itself to the furtherance of

33. BRUCE ACKERMAN, WE THE PEOPLE (1991).

34. WOMEN AND HUMAN DEVELOPMENT, supra note 2, at 14, 76. 
the well being of citizens. It also, arguably, suggests a quasi contractual, neo-Hobbesian, hypothetical moment in which citizens renounce tools of anarchic self help in order to re-constitute their political lives in some collective fashion, and re-constitute them so as to recognize the need and utility of collectivity. If Nussbaum is correct to argue that all of the "fundamental capabilities," and not just the quasi-Hobbesian capability of living a life of normal duration, are what make us "truly human," then constitutional bargains might be understood, minimally, as a conveyance from "the people" to the state of some responsibility for ensuring the minimal conditions for their flourishing. Then it might be fair to conclude that the existence of a constitution itself, particularly given an illusion at the outset in our own constitution, to "We the People," evidences a sort of contractual authority for the capabilities approach. If so, then while all states ought to protect the fundamental capabilities of citizens, constitutional states must do so, and they must do so because we the people have authoritatively proclaimed as much. That authorization, in effect, is at the heart of the constitutional pact.

And finally, the Constitution might "authorize" the capabilities approach in a rather different way: it may be that what distinguishes constitutional states from non-constitutional states, is that in a constitutional state, distinctively, citizens have rights to make demands upon their governments, the core entitlement of which is to be treated with dignity and as fully human, by their state. Constitutionalism distinctively confers rights on citizens, and confers a specific type of right: the right to be treated with dignity - and as fully human - by the state. ${ }^{35}$ Constitutional rights, so understood, are not "natural rights," which Nussbaum correctly distinguishes from legal rights; natural rights are simply a listing of what ought to be-of what states ought to do. ${ }^{36}$ Nor, though, are constitutional rights just a variant of "legal rights" per se: legal rights are simply whatever states do in fact provide. Constitutional rights, or what Dworkin sometimes (confusingly) calls "institutional rights," by contrast to both, are what citizens are entitled to demand of, specifically, constitutional governments: the "point," or "purpose," of constitutionalism is precisely to create a state that recognizes the existence of such rights. ${ }^{37}$ Furthermore, and as Dworkin and others have argued, the content of those rights must derive from some morally best political theory of our human nature--of what it means to be truly human, of what it means to be treated with dignity. If Nussbaum is

\footnotetext{
35. See RONALD DWORKIN, TAKING RIGHTS SERIOUSLY (1977).

36. WOMEN AND HUMAN DEVELOPMENT, supra note 2, at 100.

37. Dworkin, supra note 35.
} 
correct that to be fully human is to be fully capable, and to be treated with dignity by the state is to be treated in such a way that those capabilities are allowed to flourish, and Dworkin correct that citizens in constitutional governments have a constitutional right to a state that treats it with dignity, then citizens in constitutional states have a right to a state that will protect, nurture and develop these basic human capabilities.

At various points in her book, Nussbaum discusses human rights, and the human rights movement, largely to criticize its vagueness, and elsewhere she discusses legal rights, but only to distinguish them from natural rights. ${ }^{38}$ Nowhere does she give the distinctive idea of a "constitutional right" its due. But the explicit reliance on constitutionalism as the vehicle for realizing the capabilities approach suggests that the inattentiveness to the existence, and import of constitutional rights, is mistaken. The connection between the capabilities approach, as what a state must do to treat it citizens with dignity, and the idea of a constitutional right - a citizen's entitlement to be treated with dignity by the state-is a powerful one, and further provides an authoritative link, otherwise missing, between the "good idea" of capabilities, and the imperative of constitutionalism. The capabilities approach, rightly understood, is not an "alternative" to a rights approach, rather, the "capabilities approach" provides the content to a constitutional approach to government, while the idea of "rights" provides in effect the moral imperative that is at the heart of constitutionalism. In a constitutional government, we have rights, the content of which is a function of the conditions under which humans are treated with dignity. It is not simply a "good idea" that states should protect citizens' capabilities. Rather, constitutional states must do so, because their citizens' have a right to such treatment.

\section{THE AUTHORITY OF CULTURE}

Nussbaum regards "practical reason" as a fundamental human capability, without which we are not truly human. ${ }^{39}$ By "practical reason," she means, among much else, the ability to choose for oneself the contents of a good life, the ability to think reflectively and critically about one's life plan, the ability to ponder on one's own, the ultimate questions regarding life's meaning and the ability to participate in and reflect upon one's culture's educational, historical, and artistic inheritance. Choice, pretty obviously, plays prominently in this understanding of life's point and purpose. To be truly human is to exercise one's capability for practical

38. WOMEN AND HUMAN DEVELOPMENT, supra note 2, at 100.

39. Id. at 79 . 
reason, and to exercise one's capability for practical reason is, quintessentially, to choose a plan of life. This emphasis on choice, the chosen life, and the critically autonomous individual marks Nussbaum's work as liberal, provides her with a critical perspective from which to criticize illiberal cultures and regimes, and helps her ward off challenges of paternalism. It also, however, at times, blinds her to both the perils and the promise of illiberal, non-autonomous, non-chosen, traditional paths of life. It blinds her, in other words, to both the dangers and the value of cultural authority.

Obviously, there are other ways to approach life, than as presenting a panoply of choices, even ideally. We do not all-even in privileged western democracies-sit down with a "Guide to Colleges and Universities," and decide, at the onset of adulthood, whether to attend a small liberal arts college or a major research university. We do not all peruse What Color is Your [Parachute], take the Myers-Briggs personality test, or ever deliberate, in any fashion, over whether to be a doctor or a lawyer, a bohemian or a company man, an artist or a mother, an atheist or a protestant; a reform or orthodox Jew; a swinging bachelor, single parent, or a family man. We may indeed have the capability for this sort of contemplation-I think it is clear we do-and it may be (although it certainly requires argument) that this sort of contemplation is necessary to a fully human life. If so, then we have a right to a state that will nurture and protect this sort of autonomous thought. But if experience is any guide, then it seems that we also, just as inarguably, have the capability for quite the opposite: for settling into, rather than settling upon, a plan of life, and doing so by complying with the dictates of tradition. We seem to have a well honed capability for submitting to, or accepting-not choosing-our role in a given order, and for seeking at most understanding-not choicefrom the waves of universal laws that roll over us and control our existence. We have the capability, even, to accept our given role in the order of things with grace, or dignity; we can submit to this universal order of things either well or badly. There is obviously a terrible risk inherent in this capability - herds of humans can be driven to all sorts of evil-but there is value in it as well, as any number of protestant hymns will tell you: 'tis, after all, a "gift" to be simple. It may be what is required to achieve a dignified life. And finally, if consensus is to be our guide, it is not at all clear that, where the idealized "liberal" and the idealized "traditional" understanding of life's purpose conflict, the votes will come down in favor of the liberal. More fatally, it is not at all clear how to make sense of the project of seeking or achieving such a consensus: the point of the traditional mode of life, is, in part, to eschew just such deliberation; one 
can not choose to avoid choice.

How can we make sense of these warring liberal and traditionalist capabilities? Clearly, if we view the capability for practical reason as paramount, then we have a "right" to a state that will nurture that capability, and free us, where need be, from the constraints of tradition, where tradition stifles our reasoning powers. We might, then, on this lexical ordering, have various first amendment rights, or equal protection rights, to be free of the stultifying forces of "traditional" sex role or racial stereotypes, or class-based assumptions about our abilities, and we might similarly have various constitutional rights to the level of state supportsuch as a publicly funded and liberal education-necessary to nurture that capacity. Traditional authority, on this view, must yield to the moral imperative of rationalism. On the other hand, if we view the capability for acquiescence, or acceptance, or submission, or traditionalism, as the paramount capability - the capability without which human life is robbed of dignity-then we have a "right" to a state that will nurture that capability, and free us, where need be, from the false allures of an existentially oppressive and culturally destructive secular rationalism. We might, then, have various constitutional "rights," including first amendment rights, to enjoy spheres of tradition, within which these paths of life and the authorities that constitute them, including divine authorities, are unthreatened by the surrounding rationalism.

Liberal theorists of the state have tried in various ways to construct rights that will honor both of these human inclinations, perhaps none more compellingly, or with greater generosity, than John Rawls. ${ }^{40}$ Constitutional theorists, particularly of the first amendment, have similarly tried to balance the various rights that protect our capability for practical reason with the various rights (sometimes the same right) that can be construed as aimed at protecting the insularity of spheres of religious, cultural, or simply traditional authority. Theories of the first amendment, furthermore, can roughly be categorized in terms of which of these "capabilities" is viewed as paramount, which is most threatened by an overly zealous state, and which is most threatened by the other, and hence in need of aggressive state protection. I don't mean to review or comment on those attempts here. My more limited point now is that a capabilities approach puts the conflict between a rationalist and a traditionalist form of life in exceptionally sharp focus: we are capable of both practical reason and submission, but these capabilities obviously undermine each other. So-while a state might nurture one or the other, it is hard to imagine it nurturing both. Yet, both

40. See John Rawls, Political Liberalism (1993). 
our capability for practical reason and our capability for gracious acceptance of our lot in life have some claim to being a capability which must be nurtured in order to give life dignity. This seemingly basic fact about our nature and about our capabilities holds within it the seeds of tremendous mischief, both in history and in theory; it is in some ways the Achilles' heel of liberalism. It poses at least a contradiction; it poses at most the threat of global disaster.

For that reason alone, it is unfortunate that Nussbaum, who may be the only person who has attempted a systematic reconceptualization of liberalism that focuses squarely on Aristotelian capabilities, rather than rights or welfare, does not simply address the conflict head on. She is, of course, aware of the occasional harms that culture generally, and religion especially, have wrought; it would be impossible to deny, as she says, that religious bodies of thought and practice have inflicted terrible wounds on women, and on their fundamental capabilities for not just practical reason, but for safety, autonomy and survival as well. Instead of frankly identifying religious practice as an obstacle to practical reason, or to women's safety or self regard, however, she instead cabins and minimizes the potential conflict, treats religions with great respect and deference, giving every benefit of the doubt, and then seeks resolutions of the problems that remain with a "balancing" test: religious liberties should be accorded great deference by the state, unless they interfere with a fundamental capability, in which case, the state is both permitted to and perhaps obligated to intervene. But this balancing test is a strategy of avoidance, and a strikingly inadequate one, as critics of the test in the first amendment context from which it is borrowed have noted for decades now, depending on how the relative values are characterized, the impact on capabilities might always be severe or never severe, the degree of deference accorded religion near-total, or near-minimal. The "balancing test" provides no guidance other than ad hoc, and reveals little to nothing about the nature of the conflict that requires it.

Nussbam does not address the conflict in our capabilities, because, true to the liberal tradition of which she is a part, she is at bottom simply unwilling to entertain the possibility that the capability for submission to authority is a fundamental human capability in need of nurturance, necessary to a dignified life, and which a state must therefore protect if it is to treat its citizens justly. Instead, she tends to re-characterize things, and to re-characterize them in ways which quite dramatically reduce the conflict: the impulse to submit to a higher authority, for example, surely central to the world's great religious traditions, is routinely described, in this book, as a seeking, searching, indeed liberal, quest for answers to life's 
imponderables. ${ }^{41}$ Submission gives way to a search; "authority" to answers coughed up by the natural world; the religious mission and the scientific method become one and the same. Correlatively, and perhaps more revealingly, systems of organized religion are consistently recharacterized in Women and Human Development as spheres of liberty within which such searching can proceed uninhibitedly, rather than spheres of authority, and the practices and modes of life they mandate are relegated to the incidental and peripheral, rather than central. Religions appear more like reading groups of freethinkers, than systems of belief and practice that authoritatively govern people's lives. To take just one example, Judaism, Catholicism and Protestantism are all identified with their reform or progressive wings, all described in a way that charitably characterizes their open-ended spirit. ${ }^{42}$ The religious impulse as a natural response, for better or worse, to a human capability for acceptance of, submission to, or an obedient stance toward an authoritative ordering, simply disappears from the description-or when it does appear, its in the mouths of critics who unfairly "stereotype" and who fail to appreciate modern reforms. ${ }^{43}$

Nussbaum is obviously in good company in refusing to concede that submissiveness may be a human capability of at least as great a prominence, in the geography of the human spirit, as the capacity for practical reason, and refusing to concede, correlatively, that culture in all its guises, but prominently in religious forms, may have more to do with authority than with liberty. But I think in part because she refuses to do so, she not only mischaracterizes the nature of an awful lot of our cultural heritage, including our religious traditions, but also badly understates both their power and their appeal. As a result, she understates both the potential for harm, as well as the possibility that a capabilities approach to governance might effectively counter that harm and the value, not only of the human capacity for obedience, but also (and more importantly) of those cultural authorities that exploit it.

\section{A. CUltural Authority AND STUNTED LIVES}

Let me start with the potential for harm, and the possibility of using a capabilities approach to counter it. Both religions and patriarchs, worldwide and through time, have counseled women to submit to their husband's or husbands' authority, to his sexual penetration, and to their own impregnation, and to do so in accordance with his will and desire, or in

41. WOMEN AND HUMAN DEVELOPMENT, supra note 2, at 168, 179, 180.

42. Id. at $180-81$.

43. Id. at 181-86 nn. $26-27$. 
accordance with their "unborn children's" needs, and most emphatically not with reference to their own will, desire, or consent, to be so penetrated or impregnated. Women's very bodies, according to any number of religious and cultural authorities, are, as a consequence, porous and in a way that has no correlate in men's lives; women's bodies are continuous with and connected to other lives and bodies, and, by virtue of cultural and religious training, to say nothing of patriarchal control and state neglect, they are so without regard to the consent, will, desire or agency of the woman rendered so connected. Religious authorities, routinely and with mind numbing similarity across cultures, have encoded and enforced this view of what it means to be female - a view that is violently at odds with the liberal separateness of each individual, with sovereign, impenetrable physical boundaries that Nussbaum (and many other liberal theorists) insist is the defining attribute of human nature. Women, though, unlike humans, if we seriously regard the authority of our cultures, are not separate, but rather, they are connected to husbands and babies; and they are so "connected," not just in terms of willfully constructed and political family ties or intimate emotional bonds, but biologically, necessarily, absolutely, always with or without their consent. This construction of female nature as at odds with human nature, firmly enforced and underscored by religious teaching, has done incomparable harm to women: it undermines their agency, their survival skills, their employability, their civic equality, their safety, and the regard in which they hold themselves and are held by others.

None of this can be wished away, and nor should it be minimized or trivialized, by insisting, as Nussbaum does in this work, that in highly secularized and radically reformed strands of some religions, "God" has no gender, and that in Judaism, traditional prayers in which men thank god they were not born female, have been abandoned. ${ }^{44}$ Batmitzvahs are indeed ubiquitous these days - at least in Hyde Park and Chevy Chase (although, contrary to Nussbaum's optimistic characterization - and as nothing but a casual observer-I have yet to hear God referred to in these reform, feminized ceremonies, whether barmitzvahs, quaker friends' meetings, or unitarian services, as anything but masculine, at least aside from joking references to P.C. excesses). These charming, celebratory and egalitarian occasions, however, increasingly popular among the most privileged participants in organized religions, hardly counter the harms occasioned, worldwide and daily, in the name of religious "freedom", practice, or authority, upon women's bodies, selves, lives and integrity.

44. Id. at 181-82. 
Again, Nussbaum does not flatly deny this harm; quite the contrary. ${ }^{45}$ What she does do, though, is relegate it to the backwater: it is the unfortunate but incidental side effect of what is essentially a fundamental aspect of human liberty, which is the individual's quest for meaning. ${ }^{46}$ If the harm is severe, Nussbaum notes, and if the harm is to a fundamental capability, she insists, the justification for deference to religious authority runs dry, and the state may be permitted (or required) to intervene. ${ }^{47}$ But as suggested above, this "balance" tries to balance that which is in fact contradictory, and at any rate, it does not provide nearly the protection she suggests for it. Indeed, in the examples she provides of this test in practice, she ends up reaching some surprising and somewhat disheartening results. First, she supports a decision by the Indian Supreme Court to permit Muslims but not Hindus to practice polygamy (with no discussion of the harms that practice occasions to women) on the grounds that that degree of deference, whether or not it interfered with women's fundamental capabilities, was owed to a minority religion. ${ }^{48}$ Second, in the United States context, and with only slight modification, she endorses not only the outcomes in Wisconsin v. Yoder ${ }^{49}$ and Pierce v. Society of Sisters ${ }^{50}$-two Supreme Court cases, in which religious authority was essentially allowed, in the name, of course, of religious "freedom," to trump a liberal and secular mandate for universal public education-but also the extraordinarily deferential stance toward religious authority embodied in the Congressional "Religious Freedom Restoration Act"-an act which, until struck by the Supreme Court as a usurpation of judicial authority, allowed religious devotees to exempt themselves from any civil law or authority that conflicted with their religious practice. She endorses RFRA (albeit with the important modification that "compelling state interests" be defined as coterminous with fundamental capabilities), ${ }^{51}$ furthermore, and suggests it as a model for developing countries, with no discussion of the havoc which that Act, had it been allowed to stand, would have wrecked on the attempts of gays and lesbians, as well as women, to achieve some measure of civic equality in those large areas of public life dominated by or influenced by religious institutions. Third, she advocates, almost as an aside, the right of Jehovah's Witnesses to exempt themselves from child

\footnotetext{
45. Id. at $186-87$.

46. Id. at 180 .

47. Id. at $198-206$.

48. Id. at 230 .

49. Wisconsin v. Yoder, 406 U.S. 205 (1972).

50. Pierce v. Society of Sisters, 268 U.S. 510 (1925).

51. WOMEN AND HUMAN DEVELOPMENT at 198-206.
} 
labor laws, and require their children to leaflet, ${ }^{52}$ on the grounds, apparently, that the Court's decision to the contrary was elitist, given the lax attitude toward child labor when that labor is encouraged or required by the more mainstream protestant denominations. None of these examples inspires confidence in the power of a "capabilities approach" balancing test to ferret out those religious practices that interfere with fundamental capabilities, particularly women's and children's fundamental capabilities. If this is the way the "balance" comes out when applied by a rigorous feminist, god help us when we submit to the authority of religious and secular judges with jurisdiction to apply the same test. A comparable story might be told about patriarchal authority: Nussbaum tends to optimistically see "associational freedom" or liberty where others might, and with good reason, see the power of fathers and husbands to enforce, through statepermitted violence and cultural influence both, a regime of obedience upon women, by virtue of which men receive women's domestic, and childrearing labor, in exchange for only bare subsistence, if that. Again, Nussbaum acknowledges this reality-the women's stories themselves attest to it-but then oddly minimizes it so as to accommodate the "associational liberties" and "religious liberties" of those with power in families.

The bottom line cost of this selective inattentiveness to the harms of culture is not so much that those harms are not trumpeted: Nussbaum does not deny that they exist, and they have received more authoritative elucidation elsewhere. The greatest cost, to my mind, of the relative inattention paid to the fact and then the harms occasioned by cultural, religious and familial authorities, in this context, is an opportunity cost: the capabilities approach could be employed far more radically, and with greater gains for women, one suspects, than it is here, were those harms more forthrightly acknowledged and regarded with the urgency they seemingly demand. One way to do so, I believe, would be to expand the list of capabilities so as to make it more directly responsive to the reality of women's lives, the fundamental human capabilities their lives evidence as well as lack, the threats to those capabilities posed by culture, patriarchy and religious authorities, and the needs women have for state assistance, if those capabilities are to be protected. I think there are at least two such "capabilities" that could be fruitfully added to Nussbaum's list of ten, both of which are currently under cultural siege world wide, and, if protected by states, would substantially improve women's chances of living a fully human life, and of being treated with dignity by states. Neither,

52. Id. at 234-35. 
furthermore, would threaten or undermine the universalist ambitions of her original list.

We might, first, want to characterize the "separateness" that Nussbaum and other liberal theorists regard as a necessary attribute of human life as a "capability" rather than an inevitable fact, and a capability that must be protected and nurtured by the state. Women as well as men have the capability of being separate from others, and of only relinquishing that separateness when they consent to doing so. This capability is often, however, and in some cultures routinely, thwarted by the imposition upon them of pregnancies to which they do not consent, which they do not want, and which will do them considerable and sometimes life-threatening harm. The imposition of those life changing, unwanted pregnancies, furthermore, typically occurs in the context of profoundly illiberal structures of authority-religious and cultural both-that do considerable damage to not only women's capability for separateness, but to the remaining ten capabilities as well. It does not help women in these coercively connected circumstances to insist counterfactually upon the logically necessary "separateness" of human life. It might, though, help these women considerably to insist upon a right to have one's capability of living separately from other human life affirmed and protected by the state: what would be clearly implied, I think, is control over one's own reproductive life, including the right to abort or avoid unconsensual pregnancies. ${ }^{53}$

Second, one might want to include, as a fundamental capability, the capability of caring for dependents without incurring the risk of severe impoverishment. Caring for dependents seems to be a capability that renders us fully human-most of us do it, all of us have benefited from it, by virtue of it we become moral and emotionally healthy adults. And, as Nussbaum notes, women overwhelmingly perform the labor involved, over a good part of their adult lives, in the care for dependents, both children and the aged, both their own children and the children of others worldwide-which would be neither here nor there, if resources were socially arranged such that they were not either impoverished or subordinated or both by virtue of so doing. As with the capability for separateness, the capability for caring without being impoverished or subordinated seems central to human identity. But also as with the capability of separateness, the capability of caring for others without

53. Eileen McDonogh's consent-based approach to reproductive freedom strongly suggests that such a capability will be central to the attempt to achieve women's civic equality. See EILEEN MCDONOGH, FROM ChOICE to CONSENT: BREAKING THE ABORTION DEADLOCK (1996). 
risking impoverishment or subordination without state protection has proven illusive: culture, typically with the active support of states, patriarchs and religious authorities all, have delegated the work and burden, but not compensation for it, to women. The capability to care for dependents without incurring impoverishment, and without state protection, in fact, is almost non-existent, given both world wide and historical cultural patterns of labor and reproduction: caregiving that does not impoverish, and does so without state protection or assistance, might be as hard to find, in civic life, as long, healthy and happy lives are hard to find in the state of nature. $^{54}$

\section{B. Cultural Authority and Human CAPABILITIES}

Nevertheless, for all of the inattentiveness in this book to the harms of cultural, familial or religious authority, the larger problem with respect to cultural authority, no less than legal authority may be the failure to address its potential value. There may well be, in other words, culturally authoritative, or theologically authoritative arguments for the proposition that states ought to promote all or at least some of the capabilities on Nussbaum's list. Nussbaum alludes to such arguments, particularly in the Indian context, and occasionally cites or quotes religious or political figures to suggest a general compatibility between the capabilities approach and various religions, but nevertheless, there is no clearly defined cultural or religious argument for the capabilities approach per se. Its not hard to see why: Nussbaum spends a good bit of this book (and a good bit of several others) aggressively defending universalist moral claims about what people need, want, are like, or are entitled to, against the various sorts of critiques lodged against proponents of such claims by cultural relativists. ${ }^{55}$ Culturally relative moral arguments, in a sense, are precisely the sorts of arguments, whether for or against her position or any other, that she wants to not just avoid, but defeat. But in so doing, she may have overshot the mark. There is a powerful and obvious reason for a capabilities approach advocate to pay more heed than does Nussbaum to the particular cultures, and traditions, and culturally inscribed truths, and traditional ways of life, of every nation state she wants to address: if it is to be each country's particular constitution, rather than international law or international norms, that is to be the vehicle for implementing capabilities, and if a "constitution" is, in part, about national identity or national myth-making,

54. Eva Kittay's LOVE'S LABOR (1998) suggests such an argument for a right to support in care-giving labor.

55. WOMEN AND HUMAN DEVELOPMENT, supra note 2, at 34-58. 
then culture and tradition are clearly relevant to and perhaps determinative of the feasibility of the capabilities approach itself. If there is, in other words, an internal, culturally specific authority, within each nation, for the proposition that a particular state must protect or promote a particular capability, that argument becomes of paramount importance, if the "implementation" of the capabilities approach is to be domestic and constitutional. Without it-without such an internal, culturally specific authority - there may be no possibility, short of international norms backed by sanctions, that a recalcitrant state could ever be moved at all toward the minimal requirements of justice. But this book provides no clear guidance as to whether or not there is any cultural, or religious, or traditional, authority, in India, the United States, or elsewhere, for the capabilities approach. Coupled with the lack of recourse to legal authority, the reader is left suspecting that there is none, although this suspicion may well be unwarranted.

There are subsidiary costs as well of this failure to recognize both the authority of culture, its potential value, and its limits: that very failure makes much of the comparative constitutional analysis in this book seem clumsy-considerably clumsier, in fact, than the underlying argument it is typically meant to address. Let me give just two examples. First, at one point, Nussbaum suggests that we surely wouldn't want to constitutionalize the distribution of domestic labor within households - and then provides as an argument for this somewhat surprisingly regressive claim nothing but the western-culture- laden observation that "we" obviously couldn't turn the matter of "who washes the dishes" into a federal case. ${ }^{56}$ But, entirely aside from the quite real possibility and desirability of doing precisely that even in the United States constitutional context, the metaphor is peculiarly inapt in the context of some of the Indian communities she's discussing: in many parts of India, domestic labor, done entirely by women and in addition to wage labor, is intense, never-ending, back-breaking, and life shortening; its not a matter of putting porcelain dishes in a Whirlwind dishwasher. In fact, two pages later, Nussbaum confusingly backtracks, and contends, following (now) scores of feminist theorists and activists, that the allocation of domestic labor must indeed be transformed into a question of public justice, rather than private convenience, if women are to be treated with even minimal dignity by states. ${ }^{57}$ The metaphoric reference here to "washing dishes" has trivialized not only the second shift phenomenon of western women, but the more debilitating and more

56. Id. at 280 .

57. Id. at $286-90$. 
extreme injustice of the Indian women whose lives Nussbaum is clearly committed to improving; the cross-cultural metaphor, in other words, has barred, it has not promoted, inter-cultural understanding.

At another point, Nussbaum endorses RFRA, the Religious Freedom Restoration Act, not just for domestic use, but for developing countries as well, as the best vehicle for balancing the need to protect the capabilities of citizens with the need to protect religious sensibilities. ${ }^{58}$ RFRA, it will be recalled, was the congressional response to the United States Supreme Court's decision in Smith, in which the Court held that American Indians who wish to ingest peyote in furtherance of religious observances, have no immunity from prosecution for violating drug laws-or from losing unemployment compensation benefits by virtue of such infractions. Congress responded to the decision by passing a law exempting practitioners of organized religions from the reach of law-thereby, in its view, "restoring" the religious freedom that had been undermined by Smith. But again, apart from the possible recklessness of RFRA domestically - the Act obviously did not bode well for, among others, gays and lesbians seeking legislation that might insure them fair housing practices, protection against employment discrimination, or full participation in civic organizations, in the face of RFRA-protected religious objectors to those laws-the notion that RFRA could be used as a model elsewhere for accommodating religious practices and beliefs and the capabilities of citizens which might come into conflict with those practices, seems almost absurd: the act was highly culturally specific. Indeed, both the act and the hostility to the Smith decision that prompted it may well have had as much to do with the foolishness of our "war on drugs," romanticization of American Indian tribal practices, and Carlos' Castenada's ridiculous but popular books celebrating peyote use among Native Americans, than anything else. The law, in other words, was a product of culture, no less than was the peyote ceremony itself. One need not be a "cultural relativist" to insist that whatever its strengths or flaws, RFRA, because it was so culturally specific, sheds no light whatsoever on Hindu-Muslim conflicts in India, and the attempts of the moderately secularized state there to minimize that conflict through accommodating minority religious traditions.

\section{CONCLUSION}

There is, lastly, and by way of conclusion, one final reason to pay

58. Id. at $212-30$. 
somewhat greater heed than Nussbaum does (at least in this book) to the authoritative lessons of culture and tradition: culture, and the traditions that comprise them, whatever their evils, and in spite of their considerable harms, much more so than the liberal state or the laws that comprise it, are the vehicles by which capabilities are transmitted. Through immersion in her culture, for the most part, a woman learns to breastfeed a baby, thread a loom, plant a seed, split logs, run a business-no less than she learns to submit to her husband, minimize her own suffering, defer to his authority and tolerate his abuse. Religious traditions at their best, are also about ways to live, and hence about capabilities as well: they instill habits of practice; rules to follow; forms to govern daily life. Liberal rights, for all their generosity, give us none of these; as Marxist critics of liberalism have noted for generations now, we can be fully endowed with rights and yet starve. To generalize the point, we can also be fully endowed with rights and incapable; incapable of a full life, of meaningful work, of intimate association, and when we are so rights-rich and capability poor, we do indeed lack dignity, and are not living fully.

Liberalism, and the starkly agnostic state it constitutes, then, could take a page or two from culture. The citizens of a state, to be treated as fully human, must have capabilities as well as rights, and as things stand, it is typically cultures, and not states, that provide lessons in how to effectuate this mandate. As states assume this responsibility, they will sometimes defer to culture and its authorities, and sometimes interfere. But if Nussbaum is right that human dignity requires states to nurture capabilities, as well as protect rights, then whether it does so through deference or intervention, the state will have to absorb, or to make its own, some of the culture's ends and some of the culture's means. The state, after all, and not just the culture, has the constitutional obligation to endow its citizens with fundamental human capabilities, and the state, not the culture, must do so equally, and toward the end of promoting citizens' well-being, liberty, and dignity. That is the basic message of this book, and it is a powerful one. One can only hope that this very good idea can somehow be made authoritative. 